\title{
Composition-Dependent Electrocatalytic Behavior of Au-Sn Bimetallic Nanoparticles in Carbon Dioxide Reduction
}

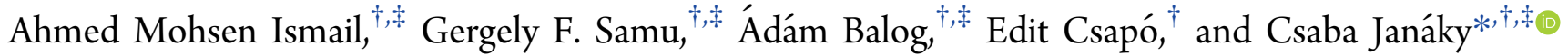 \\ †Department of Physical Chemistry and Materials Science, Interdisciplinary Excellence Centre and ${ }^{\ddagger}$ MTA-SZTE "Lendület" \\ Photoelectrochemistry Research Group, University of Szeged, Rerrich Square 1, Szeged H-6720, Hungary
}

Supporting Information

ABSTRACT: Bimetallic electrocatalysts offer great flexibility to tailor the activity and selectivity in electrochemical carbon dioxide $\left(\mathrm{CO}_{2}\right)$ reduction. Here, we report on the electrocatalytic behavior of $\mathrm{Au}-\mathrm{Sn}$ bimetallic nanoparticles with different intermetallic phases toward $\mathrm{CO}_{2}$ electroreduction. Two high-value products formed with reasonable current density: formic acid in the liquid phase and syngas $\left(\mathrm{CO}+\mathrm{H}_{2}\right)$ in the gas phase. Notably, the phase composition of the catalysts had a massive influence on both activity and product distribution. Selective isotopic labeling studies emphasized the role of bicarbonate as the source of $\mathrm{CO}$ and formic acid formation on the AuSn bimetallic phase. In situ Raman spectroelectrochem-

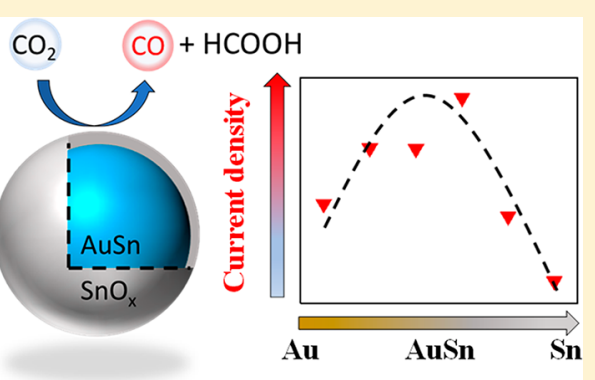
ical studies also demonstrated that the catalytic performance of the AuSn phase was superior to that of its parent metal and other bimetallic counterparts. The achieved control over the product distribution demonstrated the promise of bimetallic nanostructures being employed as efficient catalysts in the electroreduction of $\mathrm{CO}_{2}$.

$\mathrm{E}$ lectrochemical reduction of $\mathrm{CO}_{2}$ to form valuable fuels and chemicals has attracted great attention as a promising step toward renewable energy utilization and storage. ${ }^{1-3}$ Reducing $\mathrm{CO}_{2}$ in aqueous solutions with high activity and selectivity is a challenging venture and requires an efficient and selective catalyst. ${ }^{4}$ Several metals have been examined as electrocatalysts ${ }^{5-8}$ with a special focus on noble metals such as gold, ${ }^{9-11}$ which selectively reduces $\mathrm{CO}_{2}$ to $\mathrm{CO}$, showing both good stability and activity. Some nonprecious metals, such as $\mathrm{Sn},{ }^{11-14}$ can selectively catalyze formic acid production. Although there are several issues (e.g., durable catalyst, reactor design, etc.) to be solved before the commercialization of such technologies can be envisioned, ${ }^{15}$ there seems to be a consensus that $\mathrm{CO}$ (and, in particular, the $\mathrm{CO}+\mathrm{H}_{2}$ mixture) and formic acid are the most appealing reduction product from an economic perspective. ${ }^{16}$ Furthermore, a recent technoeconomic analysis suggested that formation of two high-value products, one in the gas phase and another in the liquid phase, is even more attractive (note the low separation cost). ${ }^{1}$

Alloying is a particularly promising approach to improve electrocatalytic performance. The enhancement can be achieved by tuning the binding strength of both the reactants and the intermediates via tailoring the geometric and electronic surface structure of the catalyst. ${ }^{18}$ Bimetallic nanoparticles (NPs) are ideal candidates to scrutinize such effects, as they can be prepared in a wide range of controlled phase compositions and morphologies. ${ }^{19,20}$ Different bimetallic NPs were studied in this vein (see Table S1), and many of them exhibited vastly different catalytic behavior compared to their parent metals. ${ }^{21-23}$ For the sake of brevity, we restrict our brief overview and discussion to bimetallic systems containing either gold or tin.

$\mathrm{Au}-\mathrm{Cu}$ NPs showed composition-dependent activity and product distribution. The $\mathrm{Au}_{3} \mathrm{Cu}$ catalyst showed the highest Faradaic efficiency (FE) for $\mathrm{CO}$ formation. The volcano-type activity trend was attributed to both geometric and electronic effects that enhanced the formation of $* \mathrm{COOH}$, the key intermediate of $\mathrm{CO}$ formation. ${ }^{18}$ Syngas composition (i.e., $\mathrm{H}_{2} /$ $\mathrm{CO}$ ratio) showed a good tunability on $\mathrm{Au}-\mathrm{Pt}$ alloys, which was attributed to the linear change in the binding strength of intermediates. $^{24} \mathrm{Au}-\mathrm{Pd}$ core-shell NPs showed that the activity and product distribution of $\mathrm{CO}_{2}$ electroreduction are linked to the shell thickness. As the palladium shell thickness increased from 1 to $10 \mathrm{~nm}$, hydrocarbons and formate formed in addition to $\mathrm{CO}$ and $\mathrm{H}_{2} .{ }^{25}$ The shell thickness dependence of the electrochemical $\mathrm{CO}_{2}$ reduction was investigated on $\mathrm{Au}-$ $\mathrm{Cu}$ nanoparticles. On cubic gold NPs with 7-8 layers of copper, hydrogen and ethylene formed with higher selectivity, whereas with more than 14 layers of copper, the particles

Received: October 18, 2018

Accepted: November 27, 2018

Published: November 27, 2018 


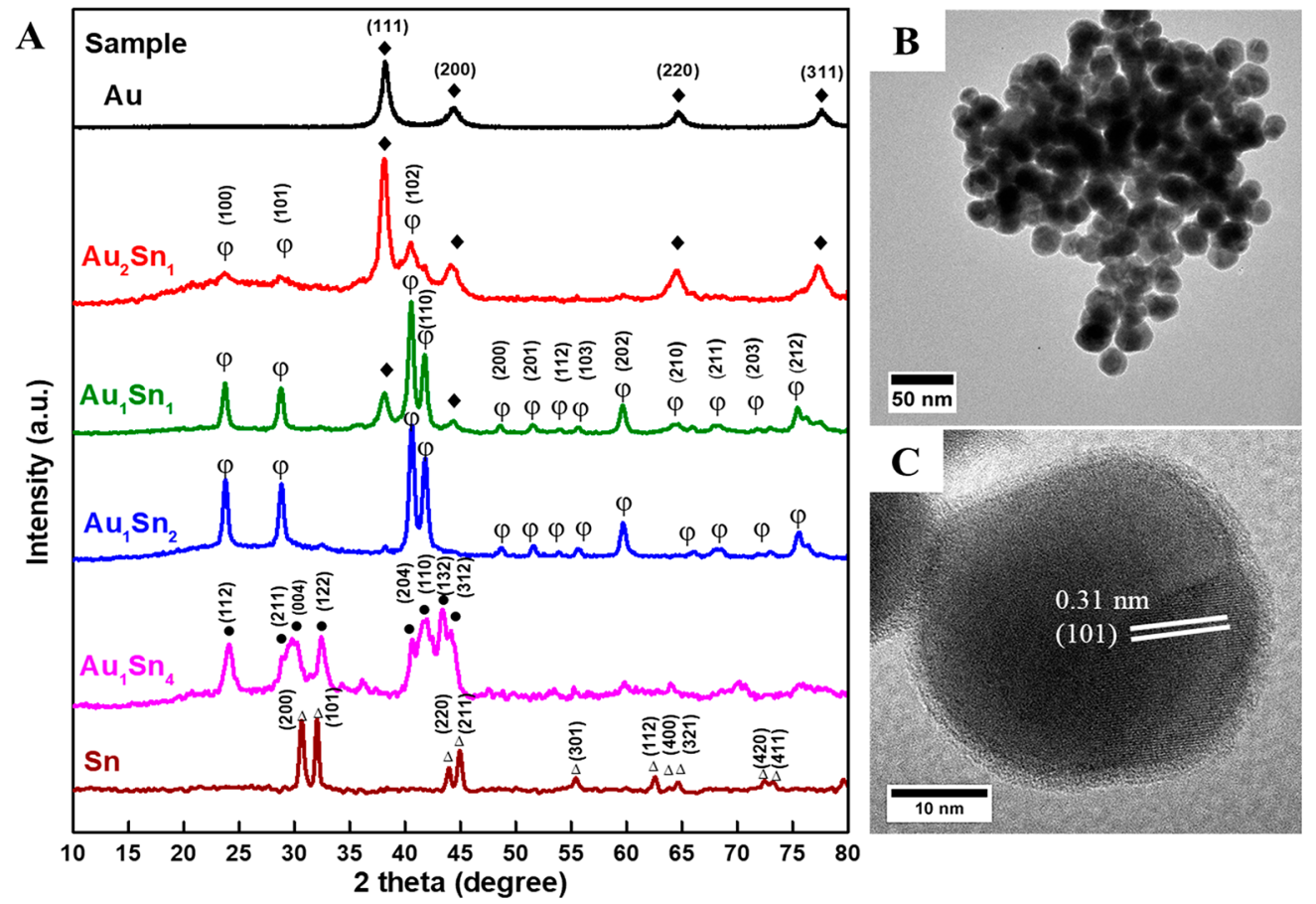

Figure 1. (A) X-ray diffraction patterns of $\mathrm{Au}-\mathrm{Sn}$ bimetallic NPs and the parent metals. The diffractions corresponding to the respective crystal phases in the samples are indicated by these marks: $(\downarrow)$ Au, $(\varphi)$ AuSn, $(\bullet)$ AuSn $_{2},(\Delta)$ Sn. (B) TEM image and (C) HRTEM image of the $\mathrm{Au}_{1} \mathrm{Sn}_{2}$ sample. Lattice fringes are highlighted together with the corresponding crystal facet.

became more selective toward the production of hydrogen and methane. ${ }^{26}$ Atomically ordered $\mathrm{AuCu}$ NPs selectively reduced $\mathrm{CO}_{2}$ to $\mathrm{CO}$, achieving $\mathrm{FE}$ of $80 \%$; in contrast, disordered $\mathrm{AuCu}$ NPs favored the hydrogen evolution reaction (HER). ${ }^{20}$ $\mathrm{Au}_{3} \mathrm{Cu}$ nanocubes with vacancy defects showed an overpotential lower than that of the $\mathrm{Au}_{3} \mathrm{Cu}$ alloy and $\mathrm{Au}$ NPs because dealloying tuned the $* \mathrm{COOH} / * \mathrm{CO}$ binding strength and the selectivity toward $\mathrm{CO}$ production. ${ }^{27} \mathrm{~A} \mathrm{Cu}-\mathrm{Sn}$ alloy resulted in the selective reduction of $\mathrm{CO}_{2}$ to $\mathrm{CO}$ with a $\mathrm{FE} \geq$ $90 \%{ }^{28} \mathrm{Cu} / \mathrm{SnO}_{2}$ core-shell NPs showed thickness-dependent $\mathrm{CO}_{2}$ reduction properties: the thicker shell $(1.8 \mathrm{~nm})$ acted like $\mathrm{SnO}_{2}$ NPs, and formate was the major product, whereas the thinner shell $(0.8 \mathrm{~nm})$ was selective toward $\mathrm{CO}$ formation with $\mathrm{FE}=93 \%{ }^{12}$ A volcano-type curve was observed between $\mathrm{FE}_{\mathrm{HCOOH}}$ and bulk tin content on $\mathrm{Ag}-\mathrm{Sn}$ electrocatalysts, having a bimetallic core and a $\mathrm{SnO}_{x}$ shell. ${ }^{4}$ Finally, the contribution of geometric and strain effects was isolated on the example of Ru-Pt NPs ( Ru@Pt core-shell and RuPt alloy). The Ru@Pt NPs with high compressive strain had HER activity in alkaline conditions that was better than that of a RuPt alloy with strain-free surface. ${ }^{29}$

To the best of our knowledge, the $\mathrm{Sn}-\mathrm{Au}$ combination has not been employed in $\mathrm{CO}_{2}$ reduction yet. This is indeed surprising, considering that gold and tin are both known to be good catalysts for electroreducing $\mathrm{CO}_{2}$ to form $\mathrm{CO}$ and $\mathrm{HCOOH}$, respectively. Here, we present the synthesis of $\mathrm{Au}-$ $\mathrm{Sn}$ bimetallic NPs with well-defined morphology and compositions and explore their composition-dependent catalytic activity toward $\mathrm{CO}_{2}$ reduction for the first time. The formation of two value-added products (syngas and formate) was demonstrated with considerable efficiency, and their ratio was tuned by changing the composition of the intermetallic phase(s).

Bimetallic $\mathrm{Au}-\mathrm{Sn}$ NPs with different nominal compositions (i.e., $\mathrm{Au}_{2} \mathrm{Sn}_{1}, \mathrm{Au}_{1} \mathrm{Sn}_{1}, \mathrm{Au}_{1} \mathrm{Sn}_{2}$, and $\mathrm{Au}_{1} \mathrm{Sn}_{4}$ ) were synthesized using a two-step synthesis approach. ${ }^{30}$ Detailed description of the synthesis is given in the Supporting Information, but briefly, this method relies on the chemical reduction of different amounts of tin precursor in the presence of premade gold NPs, ${ }^{31}$ acting as nucleation seeds. The crystal structure of the NPs was determined using powder X-ray diffraction (XRD) (Figure 1A). The pure gold showed peaks at $2 \theta=$ $38.14,44.44,64.71$, and $77.73^{\circ}$ corresponding to face-centered cubic phase of gold. The bimetallic phases showed distinctly different XRD patterns, confirming that new phases were formed (i.e., no simple alloying occurred). The $\mathrm{Au}_{2} \mathrm{Sn}_{1}$ sample had additional peaks at $2 \theta$ of $23.67,28.74$, and $40.53^{\circ}$ assigned to the hexagonal AuSn intermetallic phase. The AuSn phase became more prevalent with further increase of $\mathrm{Sn}^{4+}$ concentration (sample $\mathrm{Au}_{1} \mathrm{Sn}_{1}$ ), and even the formation of phase-pure $\mathrm{AuSn}$ was obtained (sample $\mathrm{Au}_{1} \mathrm{Sn}_{2}$ ). A different diffraction pattern was observed at the highest tin concentration (sample $\mathrm{Au}_{1} \mathrm{Sn}_{4}$ ), associated with the orthorhombic intermetallic $\mathrm{AuSn}_{2}$ phase. The pure tin exhibited a tetragonal phase. Rietveld refinement of the diffraction patterns was carried out to quantify these trends (Figure S1 and Table S2). The morphology of the Au-Sn NPs and their monometallic counterparts was characterized by transmission electron microscopy (TEM). Gold NPs were mainly spherical and crystalline, with an average diameter of $22.4 \pm 2.2 \mathrm{~nm}$ (Figure S2). After the incorporation of tin, the size of the NPs was 23.0 $\pm 2.9,31.8 \pm 3.9,32.4 \pm 3.7$, and $33.0 \pm 2.5 \mathrm{~nm}$ in the series of samples with growing tin content (Figures S3-S6).

The chemical nature of the NP surface was characterized by XPS. Figure S7 shows the XPS fitting of Au 4f and Sn 3d spectra for the four bimetallic samples. The amount of the partially oxidized tin species on the surface increased gradually with the total tin concentration: the sample with the highest tin content $\left(\mathrm{Au}_{1} \mathrm{Sn}_{4}\right)$ exhibited only a single $\mathrm{Sn} 3 \mathrm{~d}$ doublet at 494.81 and $486.15 \mathrm{eV}$ that corresponded to $\mathrm{Sn}^{4+/ 2+}$. A minor, 

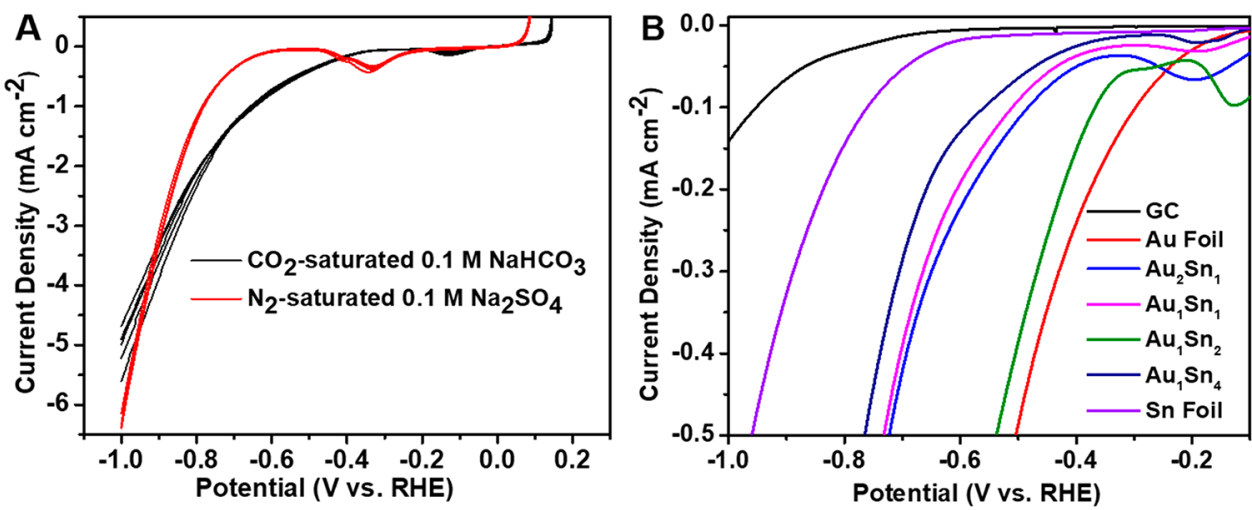

Figure 2. (A) LSV profiles of $\mathrm{Au}_{1} \mathrm{Sn}_{2}$ catalyst recorded in $\mathrm{CO}_{2}$-saturated $0.1 \mathrm{~mol} \mathrm{dm}{ }^{-3} \mathrm{NaHCO}_{3}$ and $\mathrm{N}_{2}-\mathrm{saturated}_{0.1} \mathrm{~mol} \mathrm{dm}^{-3} \mathrm{Na}_{2} \mathrm{SO}_{4}$. Scan rate $=5 \mathrm{mV} \mathrm{s}^{-1}$. (B) LSV profiles of Au-Sn NPs and gold and tin foils, recorded in $\mathrm{CO}_{2}$-saturated $0.1 \mathrm{~mol} \mathrm{dm}^{-3} \mathrm{NaHCO}_{3}$ stabilized after multiple cycles. The black line indicates the activity of the bare glassy carbon substrate. Scan rate $=5 \mathrm{mV} \mathrm{s}$. The loading was $0.35 \mathrm{mg}$ $\mathrm{cm}^{-2}$ in all cases.
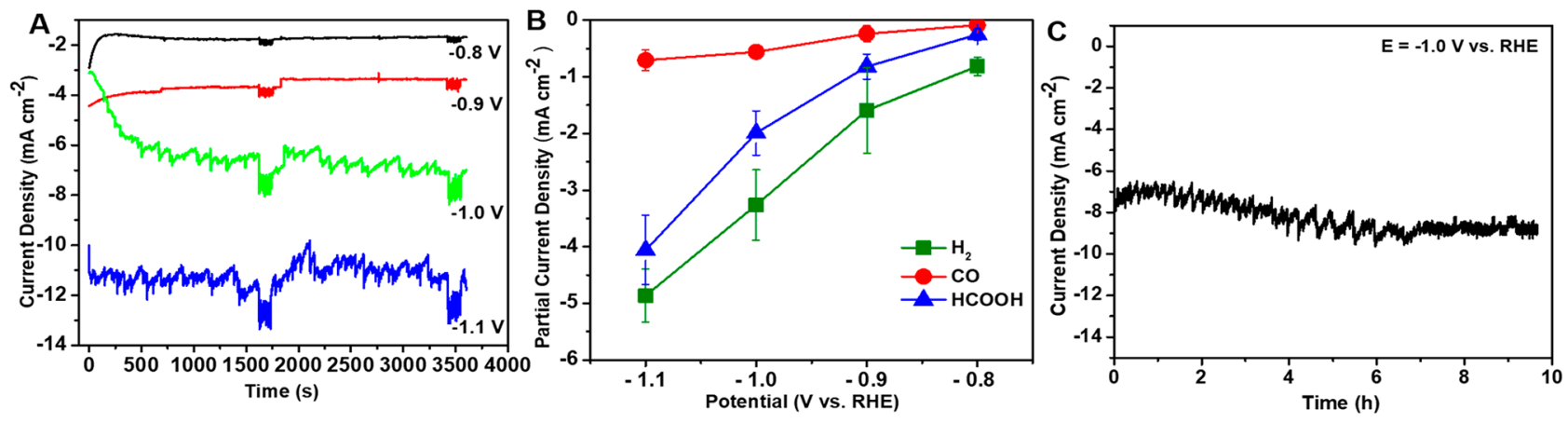

Figure 3. Electrochemical $\mathrm{CO}_{2}$ reduction performance of the $\mathrm{Au}_{1} \mathrm{Sn}_{2}$ catalyst: $(\mathrm{A})$ total current density as the function of time at various potentials, (B) $\mathrm{HCOOH}, \mathrm{CO}$, and $\mathrm{H}_{2}$ partial current densities, and (C) long-term stability measured in $\mathrm{CO}_{2}$-saturted $0.1 \mathrm{M} \mathrm{NaHCO}_{3}$ at -1.0 $\mathrm{V}$ vs RHE. Error bars represent the standard deviation, obtained by studying three different electrodes.

but significant, shift in the $\mathrm{Au} 4 \mathrm{f}$ peaks to higher binding energy was observed with increasing tin content as a result of alloying. ${ }^{32}$ The bulk composition was analyzed with EDX. The atomic percentages of gold and tin are listed in Table S3, together with the surface composition obtained from XPS. The atomic ratios of constituent metals are close to the stoichiometric molar ratio in the bulk, but not on the surface. It seems that there is always an excess tin on the surface, regardless of the bulk phase composition.

The electrochemical reduction of $\mathrm{CO}_{2}$ was first studied by linear sweep voltammetry (LSV). The onset potential in the $\mathrm{CO}_{2}$-saturated solution was notably less negative compared to that in $\mathrm{N}_{2}$-saturated solution $\left(E=-0.37 \mathrm{~V}\right.$ in $\mathrm{CO}_{2}$ and -0.65 $\mathrm{V}$ in $\mathrm{N}_{2}$ vs RHE; see Figure $2 \mathrm{~A}$ ). This observation indicated that an additional process occurred in the $\mathrm{CO}_{2}$-saturated solution, which requires less overpotential, compared to the one occurring in $\mathrm{N}_{2}$-saturated solution (i.e., HER). ${ }^{12}$ When comparing the voltammetric curves recorded in $\mathrm{CO}_{2}$-saturated $0.1 \mathrm{~mol} \mathrm{dm}^{-3} \mathrm{NaHCO}_{3}$ for the different $\mathrm{Au}-\mathrm{Sn}$ electrodes, we observed a clear shift in the onset potentials (Figure 2B; also see Figures S9 and S10 for the full LSV curves). Importantly, the trend in the onset potential values does not exactly reflect the change in the composition. This can be rationalized by the fact that new bimetallic phases are formed (rather than simple alloying), which in turn results in a nonlinear change in the bulk and surface energetics, dictating the $\mathrm{CO}_{2}$ reduction properties. Also note that these differences in the onset potential are rather substantial as the total range spans through $440 \mathrm{mV}$ !

The $\mathrm{CO}_{2}$ reduction performance of the bimetallic NPs was evaluated under chronoamperometric conditions. The detected $\mathrm{CO}_{2}$ reduction products were $\mathrm{CO}$ and formate, whereas the remaining charge was attributed to the HER. The total current density values recorded for the $\mathrm{Au}_{1} \mathrm{Sn}_{2}$ catalyst at different potentials are presented in Figure 3 as an example, together with the partial current density values for the various products. Relatively stable currents were measured during the electrolysis for all compositions, and its value increased with the overpotential (Figure S11). At $-1.1 \mathrm{~V}$ vs RHE, a stable current of $11 \mathrm{~mA} \mathrm{~cm}-2$ was achieved with a $\mathrm{FE}_{\text {formate }}$ of $42 \%$, whereas the decrease in the current and $\mathrm{FE}_{\text {formate }}$ was seen at lower overpotentials (with the parallel rise of HER activity). Tuning the composition, however, altered this trend (Figure S11), as a $\mathrm{FE}_{\text {formate }}$ of $51 \%$ was observed at $-0.9 \mathrm{~V}$ vs $\mathrm{RHE}$ over $\mathrm{Au}_{1} \mathrm{Sn}_{4}$ catalyst, which decreased to $29 \%$ at more negative potential ( $-1.1 \mathrm{~V}$ vs RHE). In addition to summarizing the above-mentioned trends for the $\mathrm{Au}_{1} \mathrm{Sn}_{2}$ catalyst, Figure $3 \mathrm{~B}$ also depicts that the formation of $\mathrm{CO}$ was rather independent from the potential, which translates to a $\mathrm{CO} / \mathrm{H}_{2}$ ratio of $1: 6-7$. The stability of $\mathrm{Au}_{1} \mathrm{Sn}_{2}$ catalyst was investigated using a twocompartment cell. The current $\left(8 \mathrm{~mA} \mathrm{~cm}{ }^{-2}\right)$ remained stable within the $10 \mathrm{~h}$ window of the experiment (Figure $3 \mathrm{C}$ ). In fact, a slight increase was witnessed in the current, due to surface roughening of the electrode. TEM analysis confirmed that the catalyst particles retained their morphology, and only a partial 

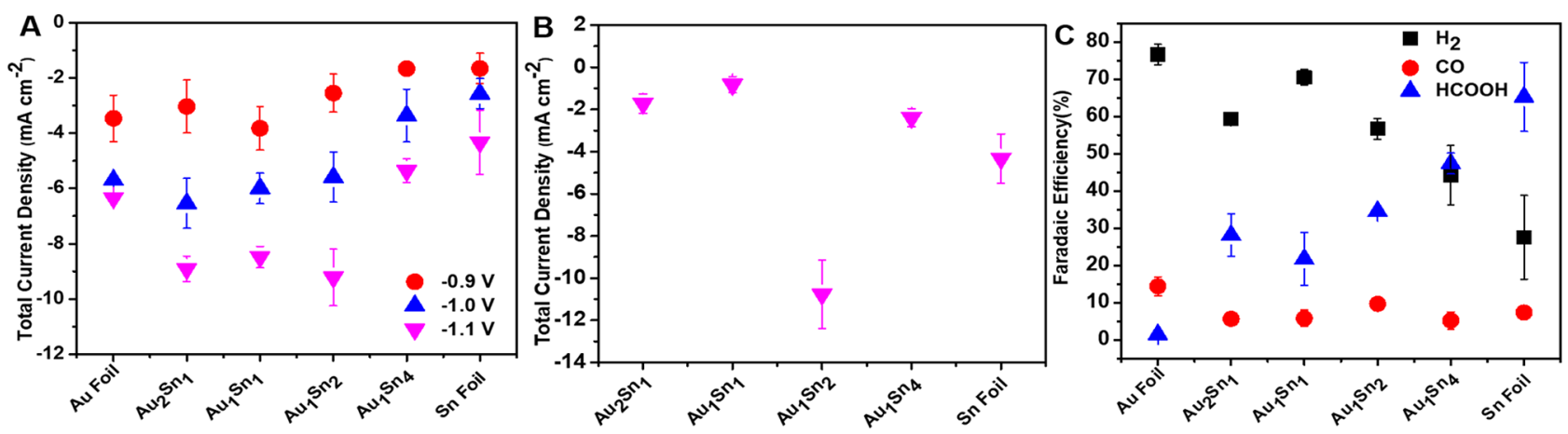

Figure 4. Electrochemical $\mathrm{CO}_{2}$ reduction activity of $\mathrm{Au}-\mathrm{Sn}$ NPs, and parent metals. (A) Total current density, (B) normalized total current density measured at $-1.1 \mathrm{~V}$ vs RHE, and (C) Faradaic efficiency values as a function of composition at $-1.0 \mathrm{~V}$ vs RHE. Error bars represent the standard deviation obtained by studying three different electrodes.
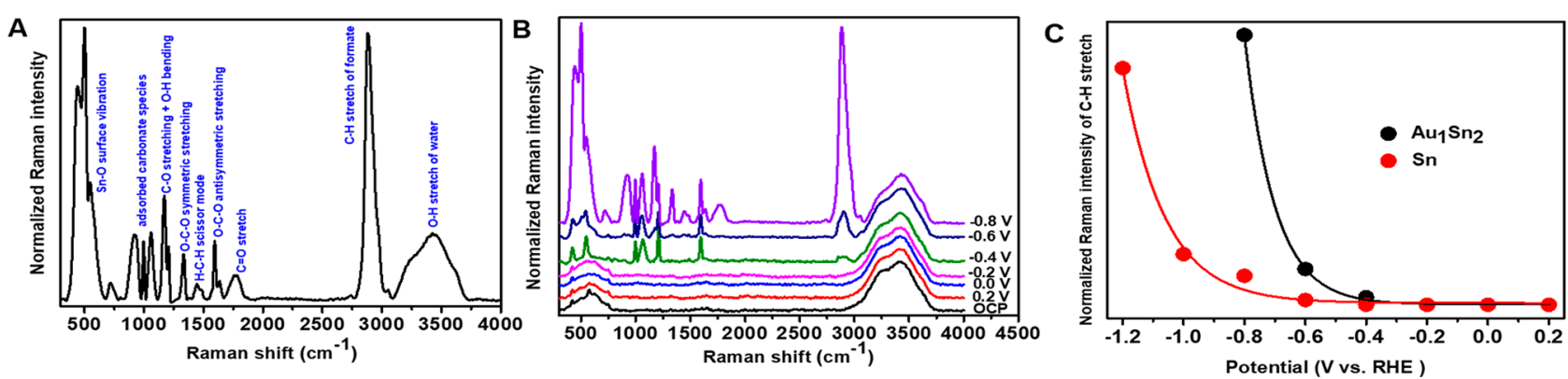

Figure 5. Raman spectra collected on $\mathrm{Au}_{1} \mathrm{Sn}_{2}$ catalyst in $\mathrm{CO}_{2}$-saturated $0.1 \mathrm{~mol} \mathrm{dm}{ }^{-3} \mathrm{NaHCO}_{3}:(\mathrm{A})$ at a potential of $-0.8 \mathrm{~V}$ vs $\mathrm{RHE}$ and $(\mathrm{B})$ as a function of the employed bias potential. (C) Potential dependence for the $\nu(\mathrm{C}-\mathrm{H})$ of formate anion at $2880 \mathrm{~cm}^{-1}$ band intensity on $\mathrm{Au}_{1} \mathrm{Sn}_{2}$ and $\mathrm{Sn} \mathrm{NP}$-coated electrodes as a function of the employed bias potential.

reduction of the $\mathrm{SnO}_{x}$ shell was observed form the TEM-EDX analysis (Figure $\mathrm{S} 12$ ), where the initial $\mathrm{O} / \mathrm{Sn}$ ratio $(0.26)$ dropped to 0.15 after electrolysis (while the $\mathrm{Au} / \mathrm{Sn}$ ratio remained constant). These data confirm that the crystalline bimetallic core and the amorphous shell are both stable under the reduction conditions, although the latter one undergoes partial reduction.

Figure $4 \mathrm{~A}$ compares the total current density values recorded for the $\mathrm{Au}-\mathrm{Sn} \mathrm{NPs}$ as well as the parent metals. At less negative potentials (i.e., $-0.9 \mathrm{~V}$ vs RHE), the gold foil exhibited the largest total current density, whereas at more negative potentials, the bimetallic samples outperformed both gold and tin. The three samples where the AuSn phase was present (see XRD analysis) showed significantly higher total current densities. This trend was further magnified when the current density was normalized with the electrochemically active surface area (Figure 4B); also see the discussion in the Supporting Information. Figure 4C shows product distribution as a function of compositions at $-1.0 \mathrm{~V}$ vs RHE. Gold foil produces about $80 \% \mathrm{H}_{2}$, whereas $\mathrm{CO}$ and formate are produced in relatively small amounts. The $\mathrm{Au}-\mathrm{Sn} \mathrm{NPs}$ produced a considerable amount of formate as the dominate reduction product is $\mathrm{CO}_{2}$. A relatively linear correlation was observed between the tin concentration in the $\mathrm{Au}-\mathrm{Sn}$ bimetallic NPs and the formate FE, whereas HER was gradually suppressed to about $44 \%$ (adding tin to gold resulted in a slower kinetics toward $\mathrm{H}_{2}$ production). The $\mathrm{FE}_{\mathrm{CO}}$, on average, was about $10 \%$, and there it showed very little composition dependence at this potential. Generally, the $\mathrm{H}_{2}$ / $\mathrm{CO}$ ratio varies in a broad range between 2.5 and 10 , depending on the composition and the potential (Figure S11). We performed a series of control experiments in which electrodes were prepared from physical mixtures of $\mathrm{Au}$ and $\mathrm{Sn}$ NPs. A physically mixed $\mathrm{Au}+\mathrm{Sn}$ electrode (1:2 molar ratio) with similar loading exhibited a much lower current density and $\mathrm{CO}_{2}$ reduction selectivity (Figure $\mathrm{S} 13$ and discussion therein). Kelvin probe measurements proved that the bimetallic nanoparticles are new chemical entities, having distinctly different electronic properties (Figure S14 and discussion therein). The reducing power (work function) alone cannot explain the trends in the catalytic activity, but there are additional factors to consider. ${ }^{33}$

Selective isotopic labeling experiments were performed to gain insights into the mechanism of $\mathrm{CO}_{2}$ reduction on $\mathrm{Au}-\mathrm{Sn}$ catalysts (see also Figure S15 and discussion therein). We found that the produced $\mathrm{CO}$ and formate originate from the aqueous $\mathrm{CO}_{2}$ supplied primarily through fast equilibrium with the bicarbonate ions in the close vicinity of the electrode rather than the purged $\mathrm{CO}_{2}$. Although the obtained trends are similar to those observed for $\mathrm{CO}_{2}$ reduction on $\mathrm{Au}-, \mathrm{Cu}-$, and $\mathrm{N}$ doped carbon surfaces, ${ }^{34-36}$ here, we confirmed a similar pattern for the production of formic acid. To gain further insights on the mechanism of the $\mathrm{CO}_{2}$ reduction process, Raman spectra were collected under electrochemical control. This allows the direct observation of reaction intermediates and/or products as they are produced during the electrochemical reaction. ${ }^{37,38}$ The spectra collected between the open circuit potential and $-0.2 \mathrm{~V}$ exhibit only bands belonging to $\mathrm{SnO}_{x}\left(482, \sim 623, \sim 772 \mathrm{~cm}^{-1}\right)^{39}$ and the $\mathrm{O}-\mathrm{H}$ stretching mode of the adsorbed water $\left(3000-3700 \mathrm{~cm}^{-1}\right.$, note that this band was almost independent from the potential) $.^{40} \mathrm{At}-0.4 \mathrm{~V}$, new bands started to appear and their intensities gradually increased at more negative potentials. The $\mathrm{SnO}_{x}$ bands became more intense and slightly shifted due to surface defects as a 
result of partial reduction. ${ }^{41,42}$ At potentials more negative than $-0.8 \mathrm{~V}$, it was quite difficult to collect Raman spectra because of the intense gas evolution. The assignments of all bands are shown in Figure 5A and summarized in Table S4. At $-0.8 \mathrm{~V}$, the spectrum showed a strong band at $2880 \mathrm{~cm}^{-1}$ and several bands of medium and weak intensity in the region of 900$1774 \mathrm{~cm}^{-1}$. These bands are similar to those observed during adsorption of formic acid on silver colloids and $\mathrm{Cu},{ }^{38,43}$ indicating the presence of formate-related and adsorbed bicarbonate species. Although the spectra recorded for $\mathrm{Au}_{1} \mathrm{Sn}_{2}$ and $\mathrm{Sn}$ NPs were similar (Figures $5 \mathrm{~B}$ and S16C), higher overpotential was required for developing the bands on Sn NPs (Figure 5C), consistent with the observed shift in the onset potential on the LSV profiles (Figure 2B).

In summary, this study proved the advantage of intermetallic phases compared to $\mathrm{Au}$ and $\mathrm{Sn}$ NPs as well as their physical mixtures. The $\mathrm{Au}_{1} \mathrm{Sn}_{2}$ catalyst (containing almost pure AuSn phase) showed the lowest overpotential for $\mathrm{CO}_{2}$ reduction, $400 \mathrm{mV}$ less negative compared to $\mathrm{Sn}$ ! Under optimal conditions, formate with high efficiency in the liquid phase and simultaneous syngas in the gas phase were obtained, as two high-value products with reasonable current density (up to $10 \mathrm{~mA} \mathrm{~cm}{ }^{-2}$ ). Comparing the activity descriptors (i.e., overpotential, current density, and product distribution) with those of other bimetallic nanoparticles in Table S1, we can conclude AuSn catalysts are indeed very promising. The superior catalytic behavior is related to the changes in the adsorption site, surface energy, and orientation of the adsorbed species. Selective isotopic labeling experiments were performed under non-equilibrium conditions, suggesting that $\mathrm{CO}_{2}$ supplied through fast equilibrium with the bicarbonate, rather than $\mathrm{CO}_{2}$ in the bulk solution, is the primary source of the produced $\mathrm{CO}$ and formate. Raman spectroelectrochemistry proved the presence of bicarbonate anions on the electrode surface under reaction conditions and confirmed the generation of formate anions at notably less negative potential on the AuSn phase compared to the pure Sn electrode.

\section{ASSOCIATED CONTENT}

\section{S Supporting Information}

The Supporting Information is available free of charge on the ACS Publications website at DOI: 10.1021/acsenergylett.8b01996.

Experimental methods, TEM and SEM images, XRD analysis, and additional electrochemical measurements (PDF)

\section{AUTHOR INFORMATION}

\section{Corresponding Author}

*E-mail: janaky@chem.u-szeged.hu. Twitter: @JanakyLab. ORCID

Csaba Janáky: 0000-0001-5965-5173

Notes

The authors declare no competing financial interest.

\section{ACKNOWLEDGMENTS}

This project has received funding from the European Research Council (ERC) under the European Union's Horizon 2020 research and innovation programme (Grant Agreement No. 716539). This research was partially supported by the "Széchenyi 2020" program in the framework of GINOP-
2.3.2-15-2016-00013 "Intelligent materials based on functional surfaces-from syntheses to applications" project and the UNKP-18-4 New National Excellence Program of the Ministry of Human Capacities". Ministry of Human Capacities, Hungary grant 20391-3/2018/FEKUSTRAT is also acknowledged.The authors thank Dr. Albert Oszkó (University of Szeged) for recording the XPS spectra, Ms. Dorottya Hursán (University of Szeged) for her support with the isotopic labeling studies, and Dr. Biborka Janáky-Bohner for her help with the manuscript preparation. A.M.I. acknowledges a scholarship from Tempus Public Foundation (TPS) and Egypt's Ministry of Higher Education and Scientific Research (MHESR).

\section{REFERENCES}

(1) Kumar, B.; Brian, J. P.; Atla, V.; Kumari, S.; Bertram, K. A.; White, R. T.; Spurgeon, J. M. New Trends in the Development of Heterogeneous Catalysts for Electrochemical $\mathrm{CO}_{2}$ Reduction. Catal. Today 2016, 270, 19-30.

(2) Whipple, D. T.; Kenis, P. J. A. Prospects of $\mathrm{CO}_{2}$ Utilization via Direct Heterogeneous Electrochemical Reduction. J. Phys. Chem. Lett. 2010, 1, 3451-3458.

(3) Janáky, C.; Hursán, D.; Endrődi, B.; Chanmanee, W.; Roy, D.; Liu, D.; de Tacconi, N. R.; Dennis, B. H.; Rajeshwar, K. Electro- and Photoreduction of Carbon Dioxide: The Twain Shall Meet at Copper Oxide/Copper Interfaces. ACS Energy Lett. 2016, 1, 332-338.

(4) Luc, W.; Collins, C.; Wang, S.; Xin, H.; He, K.; Kang, Y.; Jiao, F. Ag-Sn Bimetallic Catalyst with a Core-Shell Structure for $\mathrm{CO}_{2}$ Reduction. J. Am. Chem. Soc. 2017, 139, 1885-1893.

(5) Hori, Y. Electrochemical $\mathrm{CO}_{2}$ Reduction on Metal Electrodes. In Modern Aspects of Electrochemistry; Vayenas, C. G., White, R. E., Gamboa-Aldeco, M. E., Eds.; Springer: New York, 2008; pp 89-189.

(6) Mistry, H.; Reske, R.; Strasser, P.; Roldan Cuenya, B. SizeDependent Reactivity of Gold-Copper Bimetallic Nanoparticles during $\mathrm{CO}_{2}$ Electroreduction. Catal. Today 2017, 288, 30-36.

(7) Ma, M.; Liu, K.; Shen, J.; Kas, R.; Smith, W. A. In Situ Fabrication and Reactivation of Highly Selective and Stable Ag Catalysts for Electrochemical $\mathrm{CO}_{2}$ Conversion. ACS Energy Lett. 2018, 3, 1301-1306.

(8) Zhao, S.; Jin, R. R.; Jin, R. R. Opportunities and Challenges in $\mathrm{CO}_{2}$ Reduction by Gold- and Silver-Based Electrocatalysts: From Bulk Metals to Nanoparticles and Atomically Precise Nanoclusters. ACS Energy Lett. 2018, 3, 452-462.

(9) Vickers, J. W.; Alfonso, D.; Kauffman, D. R. Electrochemical Carbon Dioxide Reduction at Nanostructured Gold, Copper, and Alloy Materials. Energy Technol. 2017, 5, 775-795.

(10) Mistry, H.; Reske, R.; Zeng, Z.; Zhao, Z.-J.; Greeley, J.; Strasser, P.; Cuenya, B. R. Exceptional Size-Dependent Activity Enhancement in the Electroreduction of $\mathrm{CO}_{2}$ over Au Nanoparticles. J. Am. Chem. Soc. 2014, 136, 16473-16476.

(11) Chen, Y.; Kanan, M. W. Tin Oxide Dependence of the $\mathrm{CO}_{2}$ Reduction Efficiency on Tin Electrodes and Enhanced Activity for Tin/Tin Oxide Thin-Film Catalysts. J. Am. Chem. Soc. 2012, 134, 1986-1989.

(12) Li, Q.; Fu, J. J.; Zhu, W. L.; Chen, Z. Z.; Shen, B.; Wu, L. H.; Xi, Z.; Wang, T. Y.; Lu, G.; Zhu, J. J.; et al. Tuning Sn-Catalysis for Electrochemical Reduction of $\mathrm{CO}_{2}$ to $\mathrm{CO}$ via the Core/Shell $\mathrm{Cu}$ / $\mathrm{SnO}_{2}$ Structure. J. Am. Chem. Soc. 2017, 139, 4290-4293.

(13) Zhang, R.; Lv, W.; Lei, L. Role of the Oxide Layer on Sn Electrode in Electrochemical Reduction of $\mathrm{CO}_{2}$ to Formate. Appl. Surf. Sci. 2015, 356, 24-29.

(14) Feaster, J. T.; Shi, C.; Cave, E. R.; Hatsukade, T.; Abram, D. N.; Kuhl, K. P.; Hahn, C.; Nørskov, J. K.; Jaramillo, T. F. Understanding Selectivity for the Electrochemical Reduction of Carbon Dioxide to Formic Acid and Carbon Monoxide on Metal Electrodes. ACS Catal. 2017, 7, 4822-4827. 
(15) Endrődi, B.; Bencsik, G.; Darvas, F.; Jones, R.; Rajeshwar, K.; Janáky, C. Continuous-Flow Electroreduction of Carbon Dioxide. Prog. Energy Combust. Sci. 2017, 62, 133-154.

(16) Jouny, M.; Luc, W.; Jiao, F. General Techno-Economic Analysis of $\mathrm{CO}_{2}$ Electrolysis Systems. Ind. Eng. Chem. Res. 2018, 57, 21652177.

(17) Verma, S.; Kim, B.; Jhong, H.-R.; Ma, S.; Kenis, P. J. A. A Gross-Margin Model for Defining Technoeconomic Benchmarks in the Electroreduction of $\mathrm{CO}_{2}$. ChemSusChem 2016, 9, 1972-1979.

(18) Kim, D.; Resasco, J.; Yu, Y.; Asiri, A. M.; Yang, P. Synergistic Geometric and Electronic Effects for Electrochemical Reduction of Carbon Dioxide Using Gold-copper Bimetallic Nanoparticles. Nat. Commun. 2014, 5, 4948.

(19) Arora, N.; Jagirdar, B. R. From $\left(\mathrm{Au}_{5} \mathrm{Sn}+\mathrm{AuSn}\right)$ Physical Mixture to Phase Pure AuSn and $\mathrm{Au}_{5} \mathrm{Sn}$ Intermetallic Nanocrystals with Tailored Morphology: Digestive Ripening Assisted Approach. Phys. Chem. Chem. Phys. 2014, 16, 11381-11389.

(20) Kim, D.; Xie, C.; Becknell, N.; Yu, Y.; Karamad, M.; Chan, K.; Crumlin, E. J.; Nørskov, J. K.; Yang, P. Electrochemical Activation of $\mathrm{CO}_{2}$ through Atomic Ordering Transformations of $\mathrm{AuCu}$ Nanoparticles. J. Am. Chem. Soc. 2017, 139, 8329-8336.

(21) Yin, Z.; Gao, D. F.; Yao, S. Y.; Zhao, B.; Cai, F.; Lin, L. L.; Tang, P.; Zhai, P.; Wang, G. X.; Ma, D.; et al. Highly Selective Palladium-Copper Bimetallic Electrocatalysts for the Electrochemical Reduction of $\mathrm{CO}_{2}$ to CO. Nano Energy 2016, 27, 35-43.

(22) He, J.; Johnson, N. J.; Huang, A.; Berlinguette, C. Electrocatalytic Alloys for $\mathrm{CO}_{2}$ Reduction. ChemSusChem 2018, 11, 48-57.

(23) Gao, D.; Zhou, H.; Cai, F.; Wang, J.; Wang, G.; Bao, X. PdContaining Nanostructures for Electrochemical $\mathrm{CO}_{2}$ Reduction Reaction. ACS Catal. 2018, 8, 1510-1519.

(24) Ma, M.; Hansen, H. A.; Valenti, M.; Wang, Z.; Cao, A.; Dong, M.; Smith, W. A. Electrochemical Reduction of $\mathrm{CO}_{2}$ on Compositionally Variant Au-Pt Bimetallic Thin Films. Nano Energy 2017, 42, $51-57$

(25) Humphrey, J. J. L.; Plana, D.; Celorrio, V.; Sadasivan, S.; Tooze, R. P.; Rodríguez, P.; Fermín, D. J. Electrochemical Reduction of Carbon Dioxide at Gold-Palladium Core-Shell Nanoparticles: Product Distribution versus Shell Thickness. ChemCatChem 2016, 8, 952960.

(26) Monzó, J.; Malewski, Y.; Kortlever, R.; Vidal-Iglesias, F. J.; Solla-Gullón, J.; Koper, M. T. M.; Rodriguez, P. Enhanced Electrocatalytic Activity of $\mathrm{Au} @ \mathrm{Cu}$ Core@shell Nanoparticles towards $\mathrm{CO}_{2}$ Reduction. J. Mater. Chem. A 2015, 3, 23690-23698.

(27) Zhu, W.; Zhang, L.; Yang, P.; Hu, C.; Dong, H.; Zhao, Z.-J.; $\mathrm{Mu}, \mathrm{R}$.; Gong, J. Formation of Enriched Vacancies for Enhanced $\mathrm{CO}_{2}$ Electrocatalytic Reduction over AuCu Alloys. ACS Energy Lett. 2018, $3,2144-2149$.

(28) Sarfraz, S.; Garcia-Esparza, A. T.; Jedidi, A.; Cavallo, L.; Takanabe, K. Cu-Sn Bimetallic Catalyst for Selective Aqueous Electroreduction of $\mathrm{CO}_{2}$ to CO. ACS Catal. 2016, 6, 2842-2851.

(29) Wang, X.; Zhu, Y.; Vasileff, A.; Jiao, Y.; Chen, S.; Song, L.; Zheng, B.; Zheng, Y.; Qiao, S.-Z. Strain Effect in Bimetallic Electrocatalysts in the Hydrogen Evolution Reaction. ACS Energy Lett. 2018, 3, 1198-1204.

(30) Yu, K.; Yao, T.; Pan, Z.; Wei, S.; Xie, Y. Structural Evolution in the Nanoscale Diffusion Process: A Au-Sn Bimetallic System. Dalt. Trans. 2009, 46, 10353.

(31) Yu, K.; Wu, Z.; Zhao, Q.; Li, B.; Xie, Y. High-TemperatureStable Au@SnO ${ }_{2}$ Core/Shell Supported Catalyst for CO Oxidation. J. Phys. Chem. C 2008, 112, 2244-2247.

(32) Taylor, J. A.; Merchant, S. M.; Perry, D. L. Study of the Oxidation of Gold-Tin Preforms Using $\mathrm{x}$-Ray Photoelectron Spectroscopy. J. Appl. Phys. 1995, 78, 5356-5361.

(33) Cheon, J. Y.; Kim, J. H.; Kim, J. H.; Goddeti, K. C.; Park, J. Y.; Joo, S. H. Intrinsic Relationship between Enhanced Oxygen Reduction Reaction Activity and Nanoscale Work Function of Doped Carbons. J. Am. Chem. Soc. 2014, 136, 8875-8878.

(34) Dunwell, M.; Lu, Q.; Heyes, J. M.; Rosen, J.; Chen, J. G.; Yan, Y.; Jiao, F.; $\mathrm{Xu}, \mathrm{B}$. The Central Role of Bicarbonate in the
Electrochemical Reduction of Carbon Dioxide on Gold. J. Am. Chem. Soc. 2017, 139, 3774-3783.

(35) Zhu, S.; Jiang, B.; Cai, W.-B.; Shao, M. Direct Observation on Reaction Intermediates and the Role of Bicarbonate Anions in $\mathrm{CO}_{2}$ Electrochemical Reduction Reaction on Cu Surfaces. J. Am. Chem. Soc. 2017, 139, 15664-15667.

(36) Hursán, D.; Janáky, C. Electrochemical Reduction of Carbon Dioxide on Nitrogen-Doped Carbons: Insights from Isotopic Labeling Studies. ACS Energy Lett. 2018, 3, 722-723.

(37) Pander, J. E.; Ren, D.; Huang, Y.; Loo, N. W. X.; Hong, S. H. L.; Yeo, B. S. Understanding the Heterogeneous Electrocatalytic Reduction of Carbon Dioxide on Oxide-Derived Catalysts. ChemElectroChem 2018, 5, 219-237.

(38) Batista, E. A.; Temperini, M. L. A. Spectroscopic Evidences of the Presence of Hydrogenated Species on the Surface of Copper during $\mathrm{CO}_{2}$ electroreduction at Low Cathodic Potentials. J. Electroanal. Chem. 2009, 629, 158-163.

(39) Dutta, A.; Kuzume, A.; Rahaman, M.; Vesztergom, S.; Broekmann, P. Monitoring the Chemical State of Catalysts for $\mathrm{CO}_{2}$ Electroreduction: An In Operando Study. ACS Catal. 2015, 5, 74987502

(40) Ichinohe, Y.; Wadayama, T.; Hatta, A. Electrochemical Reduction of $\mathrm{CO}_{2}$ on Silver as Probed by Surface-Enhanced Raman Scattering. J. Raman Spectrosc. 1995, 26, 335-340.

(41) Kar, A.; Kundu, S.; Patra, A. Surface Defect-Related Luminescence Properties of $\mathrm{SnO}_{2}$ Nanorods and Nanoparticles. $J$. Phys. Chem. C 2011, 115, 118-124.

(42) Dutta, A.; Kuzume, A.; Kaliginedi, V.; Rahaman, M.; Sinev, I.; Ahmadi, M.; Roldán Cuenya, B.; Vesztergom, S.; Broekmann, P. Probing the Chemical State of Tin Oxide NP Catalysts during $\mathrm{CO}_{2}$ Electroreduction: A Complementary Operando Approach. Nano Energy 2018, 53, 828-840.

(43) Castro, J. L.; Otero, J. C.; Marcos, J. I. Anomalous SERS of Monocarboxylic Acids on Silver Sols. J. Raman Spectrosc. 1997, 28, $765-769$. 